\title{
Methionine Restriction: Ready for Prime Time in the Cancer Clinic?
}

\author{
JUN YAMAMOTO ${ }^{1,2,3}$, QINGHONG HAN ${ }^{1}$, MARK SIMON $^{4}$, DANIEL THOMAS ${ }^{5}$ and ROBERT M. HOFFMAN ${ }^{1,2}$ \\ ${ }^{1}$ AntiCancer Inc., San Diego, CA, U.S.A.; \\ ${ }^{2}$ Department of Surgery, University of California, San Diego, La Jolla, CA, U.S.A.; \\ ${ }^{3}$ Department of Gastroenterological Surgery, \\ Yokohama City University Graduate School of Medicine, Yokohama, Japan; \\ ${ }^{4}$ Nutritional Oncology Research Institute, Westlake Village, CA, U.S.A.; \\ ${ }^{5}$ Healthy and Strong, Mount Dora, FL, U.S.A.
}

\begin{abstract}
Attempts to selectively starve cancers in the clinic have been made at least since the time of Warburg beginning 100 years ago. Calorie-restriction or low-carbohydrate diets have had limited success with cancer patients. Methionine restriction is another strategy to selectively starve cancer cells, since cancers are addicted to methionine, unlike normal cells. Methionine addiction of cancer is termed the Hoffman effect Numerous preclinical studies over the past half century have shown methionine restriction to be highly effective against all major cancer types and synergistic with chemotherapy. Lowmethionine medical diets can be effective in lowering methionine and have shown some clinical promise, but they are not palatable and thereby not sustainable. However, selectively choosing among plant-based foods allows a variety of lowmethionine diets that are sustainable. Our laboratory has developed a methioninase that can be administered orally as a supplement and has resulted in anecdotal positive results in patients with advanced cancer, including hormone-independent prostate cancer, and other recalcitrant cancers. The question is whether methionine restriction through a low-methionine diet, or even greater methionine restriction with methioninase in combination with a low-methionine diet, is ready for prime
\end{abstract}

This article is freely accessible online.

Correspondence to: Robert M. Hoffman, Ph.D., AntiCancer Inc, 7917 Ostrow St, San Diego, CA, 92111, U.S.A. Tel: +1 8586542555, Fax: +1 8582684175, e-mail: all@anticancer.com; Jun Yamamoto, MD, AntiCancer Inc, 7917 Ostrow St, San Diego, CA, 92111, U.S.A. Tel: +1 8586542555, Fax: +1 8582684175, e-mail: jun.ymmt.1014@gmail.com

Key Words: Cancer, methionine addiction, Hoffman effect, methionine restriction, methioninase, clinical treatment, review. time in the clinic, especially in combination with other synergistic therapy. The question will hopefully be answered in the near future, especially for advanced cancer patients who have failed all standard therapy.

Otto Warburg observed in the late 1920s that cancer cells used glycolysis to metabolize glucose, an anaerobic process, even in the presence of oxygen. Warburg's hypothesis was that cancer cells had defective mitochondria and could not carry out oxidative phosphorylation (1). This is called the Warburg effect. Warburg's idea was that cancer cells could be starved to death by depriving them of energy. The study of the Warburg effect has been revived in the $21^{\text {st }}$ century (2) and it is hypothesized that the Warburg effect is a property of rapidly proliferating cells - both cancer and nonmalignant, whereby the intermediate metabolites of glucose are converted into biomass as well as energy.

However, depriving tumors of energy involves starving the whole body of energy. Hints of a better way to starve cancer cells come from different sources. The first hint came from Sugimura et al. (3) who observed that removal of the aminoacid methionine from the diet of rats with tumors slowed tumor growth more than when other amino-acids were removed from the diet. Another important hint came from positron emission tomography (PET) imaging in the clinic where PET images of tumors obtained with $\left[{ }^{11} \mathrm{C}\right]$ methionine were compared to PET images obtained with $\left[{ }^{18} \mathrm{~F}\right]$ deoxyglucose, whereby the images with $\left[{ }^{11} \mathrm{C}\right]$ methionine had a stronger signal and were more specific than images obtained with the $\left[{ }^{18} \mathrm{~F}\right]$ deoxyglucose analog of glucose $(4,5)$. These results suggest that differences between cancer cells and normal cells in their requirement for methionine may be larger than their differences in their requirement for glucose. Cancers of all types have been shown to be methionine-addicted $(6,7)$. 
Another important hint came from the discovery how cancers are addicted to methionine: cancer cells can biosynthesize methionine from its immediate precursor homocysteine at normal or higher rates, but still require large amounts of methionine for excess transmethylation reactions, in contrast to normal cells of all types (8-12). It appears that methionine addiction is a universal hallmark of cancer and is is termed the Hoffman effect. Important early studies showed that methionine-restricted (MR) cancer cells selectively arrest in late $S / G_{2}$ of the cell cycle (13). This unusual cell-cycle arrest was exploited to demonstrate that cell-cycle-specific cancer chemotherapy was very effective when combined with MR (14-16).

Recently Locasale et al found that normal people on a low-methionine diet re-programmed their methionine metabolism (17).

The enzyme methionine $\gamma$-lyase (methioninase) was first used for cancer treatment in a mouse model in 1973 (18). Soda et al. (19) and Tan et al (20) subsequently developed a methioninase from Pseudomonas putida and later cloned it in $E$. coli, thereby establishing recombinant methioninase (rMETase). Methioninase was tested in cancer patients for its ability to deplete circulating methionine after intravenous injection (i.v.). Methionine was rapidly depleted to undetectable levels in the patients with no adverse effects $(21,22)$. rMETase was then tested by i.v. administration in macaque monkeys and found to cause anaphylacsis unless the rMETase was conjugated to polyethylene glycol (PEG) $(23,24)$. This made methioninase difficult to develop as a clinical therapeutic.

However in 2017, we showed that methioninase was highly effective when administered orally (o-rMETase) in patient-derived orthotopic xenograft (PDOX) models of various cancers. For example, o-rMETase could overcome gemcitabine resistance in a PDOX model of pancreatic cancer (25). o-rMETase overcame chemotherapy-resistance in sarcoma (26-28) and triple-negative breast cancer $(29,30)$. Early clinical studies have shown that o-rMETase decreases or stabilizes prostate specific antigen (PSA) levels in patients with advanced-prostate cancer with no adverse effects (3133). Currently, approximately 40 patients with advanced cancer are taking o-rMETase as a supplement.

\section{Future Directions}

Currently o-rMETase is given to cancer patients as a supplement. o-rMETase can also be developed as a drug in the future. In the near future, o-rMETase, as a supplement, will be given to patients to enhance chemotherapy, especially combined with agents that inhibit DNA synthesis or antimitotic agents, including 5-fluoruracil (5-FU), cisplatinum, gemcitabine, and paclitaxel, which have been shown to be effective in combination with o-rMETase in PDOX models (34-36). The patients taking o-rMETase are urged to also have a low-methionine diet (37). It is hoped in the near future, that methionine restriction, with both a lowmethionine diet and o-rMETase, will be ready for prime time in the clinic, especially in combination with synergistic therapy, for advanced cancer patients who have failed standard therapy. The combination of rMETase, a methioninerestricted diet and synergistic chemotherapy has been shown to be very effective in a mouse-model of brain cancer (38). Early clinical trials of nutritional MR, with and without chemotherapy showed promising results in some advanced cancer patients. Epner was among the first to administer cancer patients a methionine-free diet and found that it may have slowed or arrested the cancer in advanced patients (39, 40). Thivat et al. (41) reported that a methionine-free diet combined with cystemustine had some efficacy in melanoma and glioma patients in a phase I clinical trial (41). Durando et al (42) reported that a methionine-free diet and FOLFOX chemotherapy had efficacy in some patients with metastatic colon cancer. Goseki et al (43) reported methionine-free total parenteral nutrition (TPN) with chemotherapy was significantly more effective than methionine-containing TPN with chemotherapy, in advanced gastro-intestinal- cancer patients. The addition of o-rMETase to regimens with methionine-free nutrition (44) and chemotherapy holds clinical promise.

\section{Conflicts of Interest}

The Authors declare that there are no potential conflicts of interest in relation to this study.

\section{Authors' Contributions}

JY and RMH: writing, review, and/or revision of the article. QH, MS, and DT gave technical support and conceptual advice.

\section{Acknowledgements}

This paper is dedicated to the memory of AR Moossa, MD; Sun Lee, MD; Professor Li Jiaxi; Masaki Kitakima, MD; and Joseph R. Bertino, MD.

\section{References}

1 Warburg O: On the origin of cancer cells. Science 123(3191): 309314, 1956. PMID: 13298683. DOI: 10.1126/science.123.3191.309

2 Vander Heiden MG, Cantley LC and Thompson CB: Understanding the Warburg effect: the metabolic requirements of cell proliferation. Science 324(5930): 1029-1033, 2009. PMID: 19460998. DOI: 10.1126/science.1160809

3 Sugimura T, Birnbaum SM, Winitz M and Greenstein JP: Quantitative nutritional studies with water-soluble, chemically defined diets. VIII. The forced feeding of diets each lacking in one essential amino acid. Arch Biochem Biophys 81(2): 448-455, 1959. PMID: 13638009. DOI: 10.1016/00039861(59)90225-5 
4 Singhal T, Narayanan TK, Jacobs MP, Bal C and Mantil JC: ${ }^{11} \mathrm{C}$ methionine PET for grading and prognostication in gliomas: a comparison study with ${ }^{18} \mathrm{~F}-\mathrm{FDG}$ PET and contrast enhancement on MRI. J Nucl Med 53(11): 1709-1715, 2012. PMID: 23055534. DOI: $10.2967 /$ jnumed.111.102533

5 Sharma R, D'Souza M, Jaimini A, Hazari PP, Saw S, Pandey S, Singh D, Solanki Y, Kumar N, Mishra AK and Mondal A: A comparison study of (11)C-methionine and (18)F-fluorodeoxyglucose positron emission tomography-computed tomography scans in evaluation of patients with recurrent brain tumors Indian J Nucl Med 31(2): 93-102, 2016. PMID: 27095856. DOI: 10.4103/0972-3919.178254

6 Mecham JO, Rowitch D, Wallace CD, Stern PH and Hoffman RM: The metabolic defect of methionine dependence occurs frequently in human tumor cell lines. Biochem Biophys Res Commun 117(2): 429-434, 1983. PMID: 6661235. DOI: 10.1016/0006-291x(83)91218-4

7 Tan Y, Xu M and Hoffman RM: Broad selective efficacy of rMETase and PEG-rMETase on cancer cells in vitro. Anticancer Res 30(3): 793-798, 2010. PMID: 20392998.

8 Hoffman RM and Erbe RW: High in vivo rates of methionine biosynthesis in transformed human and malignant rat cells auxotrophic for methionine. Proc Natl Acad Sci USA 73(5): 1523-1527, 1976. PMID: 179090. DOI: 10.1073/pnas.73.5.1523

9 Coalson DW, Mecham JO, Stern PH and Hoffman RM: Reduced availability of endogenously synthesized methionine for Sadenosylmethionine formation in methionine-dependent cancer cells. Proc Natl Acad Sci USA 79(14): 4248-4251, 1982. PMID: 6289297. DOI: $10.1073 /$ pnas.79.14.4248

10 Stern $\mathrm{PH}$ and Hoffman RM: Elevated overall rates of transmethylation in cell lines from diverse human tumors. In Vitro - Rapid Commun in Cell Biology 20: 663-670, 1984. PMID: 6500606. DOI: 10.1007/BF02619617

11 Wang Z, Yip LY, Lee JHJ, Wu Z, Chew HY, Chong PKW, Teo CC, Ang HY, Peh KLE, Yuan J, Ma S, Choo LSK, Basri N, Jiang X, Yu Q, Hillmer AM, Lim WT, Lim TKH, Takano A, Tan EH, Tan DSW, Ho YS, Lim B and Tam WL: Methionine is a metabolic dependency of tumor-initiating cells. Nat Med 25(5): 825-837, 2019. PMID: 31061538. DOI: 10.1038/s41591-0190423-5

12 Stern PH, Mecham JO, Wallace CD and Hoffman RM: Reduced free-methionine in methionine-dependent SV40-transformed human fibroblasts synthesizing apparently normal amounts of methionine. J Cell Physiol 117(1): 9-14, 1983. PMID: 6311851. DOI: $10.1002 /$ jcp. 1041170103

13 Hoffman RM and Jacobsen SJ: Reversible growth arrest in simian virus 40-transformed human fibroblasts. Proc Natl Acad Sci USA 77(12): 7306-7310, 1980. PMID: 6261250. DOI: 10.1073/pnas.77.12.7306

14 Stern PH and Hoffman RM: Enhanced in vitro selective toxicity of chemotherapeutic agents for human cancer cells based on a metabolic defect. J Natl Cancer Inst 76(4): 629-639, 1986. PMID: 3457200. DOI: 10.1093/jnci/76.4.629

15 Hoshiya Y, Kubota T, Inada T, Kitajima M and Hoffman RM: Methionine-depletion modulates the efficacy of 5-fluorouracil in human gastric cancer in nude mice. Anticancer Res 17(6D): 4371-4375, 1997. PMID: 9494535.

16 Yoshioka T, Wada T, Uchida N, Maki H, Yoshida H, Ide N, Kasai H, Hojo K, Shono K, Maekawa R, Yagi S, Hoffman RM and Sugita K: Anticancer efficacy in vivo and in vitro, synergy with 5-fluorouracil, and safety of recombinant methioninase. Cancer Res 58(12): 2583-2587, 1998. PMID: 9635582.

17 Gao X, Sanderson SM, Dai Z, Reid MA, Cooper DE, Lu M, Richie JP Jr, Ciccarella A, Calcagnotto A, Mikhael PG, Mentch SJ, Liu J, Ables G, Kirsch DG, Hsu DS, Nichenametla SN and Locasale JW: Dietary methionine influences therapy in mouse cancer models and alters human metabolism. Nature 572(7769): 397-401, 2019. PMID: 31367041. DOI: $10.1038 / \mathrm{s} 41586-019-1437-3$

18 Kreis $W$ and Hession C: Biological effects of enzymatic deprivation of L-methionine in cell culture and an experimental tumor. Cancer Res 33(8): 1866-1869, 1973. PMID: 4720798.

19 Tanaka H, Esaki N and Soda K: A versatile bacterial enzyme: 1methionine $\gamma$-lyase. Enzyme Microb Technol 7(11): 530-537, 1985. DOI: 10.1016/0141-0229(85)90094-8

20 Tan Y, Xu M, Tan X, Tan X, Wang X, Saikawa Y, Nagahama T, Sun X, Lenz M and Hoffman RM: Overexpression and largescale production of recombinant L-methionine-alpha-deaminogamma-mercaptomethane-lyase for novel anticancer therapy. Protein Expr Purif 9(2): 233-245, 1997. PMID: 9056489. DOI: 10.1006/prep.1996.0700

21 Tan Y, Zavala J Sr., Xu M, Zavala J Jr. and Hoffman RM: Serum methionine depletion without side effects by methioninase in metastatic breast cancer patients. Anticancer Res 16(6C): 39373942, 1996. PMID: 9042316.

22 Tan Y, Zavala J Sr, Han Q, Xu M, Sun X, Tan X, Tan X, Magana R, Geller $\mathrm{J}$ and Hoffman RM: Recombinant methioninase infusion reduces the biochemical endpoint of serum methionine with minimal toxicity in high-stage cancer patients. Anticancer Res 17(5B): 3857-3860, 1997. PMID: 9427792.

23 Yang Z, Wang J, Lu Q, Xu J, Kobayashi Y, Takakura T, Takimoto A, Yoshioka T, Lian C, Chen C, Zhang D, Zhang Y, Li S, Sun X, Tan Y, Yagi S, Frenkel EP and Hoffman RM: PEGylation confers greatly extended half-life and attenuated immunogenicity to recombinant methioninase in primates. Cancer Res 64(18): 6673-6678, 2004. PMID: 15374983. DOI: 10.1158/0008-5472.CAN-04-1822

24 Yang Z, Wang J, Yoshioka T, Li B, Lu Q, Li S, Sun X, Tan Y, Yagi S, Frenkel EP and Hoffman RM: Pharmacokinetics, methionine depletion, and antigenicity of recombinant methioninase in primates. Clin Cancer Res 10(6): 2131-2138, 2004. PMID: 15041734. DOI: 10.1158/1078-0432.ccr-03-0068

25 Kawaguchi K, Miyake K, Han Q, Li S, Tan Y, Igarashi K, Kiyuna T, Miyake M, Higuchi T, Oshiro H, Zhang Z, Razmjooei S, Wangsiricharoen S, Bouvet M, Singh SR, Unno $M$ and Hoffman RM: Oral recombinant methioninase (o-rMETase) is superior to injectable rMETase and overcomes acquired gemcitabine resistance in pancreatic cancer. Cancer Lett 432: 251-259, 2018. PMID: 29928962. DOI: 10.1016/j.canlet.2018.06.016

26 Higuchi T, Kawaguchi K, Miyake K, Han Q, Tan Y, Oshiro H, Sugisawa N, Zhang Z, Razmjooei S, Yamamoto N, Hayashi K, Kimura H, Miwa S, Igarashi K, Chawla SP, Singh AS, Eilber FC, Singh SR, Tsuchiya $H$ and Hoffman RM: Oral recombinant methioninase combined with caffeine and doxorubicin induced regression of a doxorubicin-resistant synovial sarcoma in a PDOX mouse model. Anticancer Res 38(10): 5639-5644, 2018. PMID: 30275182. DOI: 10.21873/anticanres.12899

27 Higuchi T, Oshiro H, Miyake K, Sugisawa N, Han Q, Tan Y, Park J, Zhang Z, Razmjooei S, Yamamoto N, Hayashi K, 
Kimura H, Miwa S, Igarashi K, Bouvet M, Chawla SP, Singh SR, Tsuchiya $\mathrm{H}$ and Hoffman RM: Oral recombinant methioninase, combined with oral caffeine and injected cisplatinum, overcome cisplatinum-resistance and regresses patient-derived orthotopic xenograft model of osteosarcoma. Anticancer Res 39(9): 4653-4657, 2019. PMID: 31519563. DOI: 10.21873/anticanres.13646

28 Higuchi T, Han Q, Miyake K, Oshiro H, Sugisawa N, Tan Y, Yamamoto N, Hayashi K, Kimura H, Miwa S, Igarashi K, Bouvet M, Singh SR, Tsuchiya $H$ and Hoffman RM: Combination of oral recombinant methioninase and decitabine arrests a chemotherapy-resistant undifferentiated soft-tissue sarcoma patient-derived orthotopic xenograft mouse model. Biochem Biophys Res Commun 523(1): 135-139, 2020. PMID: 31839218. DOI: 10.1016/j.bbrc.2019.12.024

29 Lim HI, Hamada K, Yamamoto J, Han Q, Tan Y, Choi HJ, Nam SJ, Bouvet $M$ and Hoffman RM: Oral methioninase inhibits recurrence in a PDOX mouse model of aggressive triplenegative breast cancer. In Vivo 34(5): 2281-2286, 2020. PMID: 32871751. DOI: 10.21873/invivo.12039

30 Lim HI, Yamamoto J, Han Q, Sun YU, Nishino H, Tashiro Y, Sugisawa N, Tan Y, Choi HJ, Nam SJ, Bouvet M and Hoffman RM: Response of triple-negative breast cancer liver metastasis to oral recombinant methioninase in a patient-derived orthotopic xenograft (PDOX) model. In Vivo 34(6): 3163-3169, 2020. PMID: 33144420. DOI: 10.21873/invivo.12151

31 Han Q, Tan Y and Hoffman RM: Oral dosing of recombinant methioninase is associated with a 70\% drop in PSA in a patient with bone-metastatic prostate cancer and $50 \%$ reduction in circulating methionine in a high-stage ovarian cancer patient. Anticancer Res 40(5): 2813-2819, 2020. PMID: 32366428. DOI: 10.21873/anticanres.14254

32 Han Q and Hoffman RM: Chronic treatment of an advanced prostate-cancer patient with oral methioninase resulted in long-term stabilization of rapidly rising PSA levels. In Vivo 35(4): 21712176, 2021. PMID: 34182494. DOI: 10.21873/invivo.12488

33 Han Q and Hoffman RM: Lowering and stabilizing PSA levels in advanced-prostate cancer patients with oral methioninase. Anticancer Res 41(4): 1921-1926, 2021. PMID: 33813397. DOI: 10.21873/anticanres.14958

34 Park JH, Zhao M, Han Q, Sun Y, Higuchi T, Sugisawa N, Yamamoto J, Singh SR, Clary B, Bouvet M and Hoffman RM: Efficacy of oral recombinant methioninase combined with oxaliplatinum and 5-fluorouracil on primary colon cancer in a patient-derived orthotopic xenograft mouse model. Biochem Biophys Res Commun 518(2): 306-310, 2019. PMID: 31421825. DOI: 10.1016/j.bbrc.2019.08.051

35 Aoki Y, Tome Y, Wu NF, Yamamoto J, Hamada K, Han Q, Bouvet M, Nishida K and Hoffman RM: Oral-recombinant methioninase converts an osteosarcoma from docetaxel-resistant to -sensitive in a clinically-relevant patient-derived orthotopicxenograft (PDOX) mouse model. Anticancer Res 41(4): 17451751, 2021. PMID: 33813378. DOI: 10.21873/anticanres.14939
36 Sugisawa N, Higuchi T, Han Q, Hozumi C, Yamamoto J, Tashiro Y, Nishino H, Kawaguchi K, Bouvet M, Murata T, Unno M and Hoffman RM: Oral recombinant methioninase combined with paclitaxel arrests recalcitrant ovarian clear cell carcinoma growth in a patient-derived orthotopic xenograft (PDOX) nude-mouse model. Cancer Chemother Pharmacol 88(1): 61-67, 2021. PMID: 33768300. DOI: 10.1007/s00280-021-04261-x

37 Nutritional Oncology Research Institute, Westlake Village, CA, USA, 2021. Available at: https://nutritionaloncology.net/ [Last accessed on December 1, 2021]

38 Kokkinakis DM, Hoffman RM, Frenkel EP, Wick JB, Han Q, Xu M, Tan Y and Schold SC: Synergy between methionine stress and chemotherapy in the treatment of brain tumor xenografts in athymic mice. Cancer Res 61(10): 4017-4023, 2001. PMID: 11358820.

39 Epner DE, Morrow S, Wilcox M and Houghton JL: Nutrient intake and nutritional indexes in adults with metastatic cancer on a phase I clinical trial of dietary methionine restriction. Nutr Cancer 42(2): 158-166, 2002. PMID: 12416254. DOI: $10.1207 /$ S15327914NC422_2

40 Epner DE: Can dietary methionine restriction increase the effectiveness of chemotherapy in treatment of advanced cancer? J Am Coll Nutr 20(5 Suppl): 443S-449S; discussion 473S-475S, 2001. PMID: 11603655. DOI: 10.1080/07315724.2001.10719183

41 Thivat E, Farges MC, Bacin F, D'Incan M, Mouret-Reynier MA, Cellarier E, Madelmont JC, Vasson MP, Chollet P and Durando $\mathrm{X}$ : Phase II trial of the association of a methionine-free diet with cystemustine therapy in melanoma and glioma. Anticancer Res 29(12): 5235-5240, 2009. PMID: 20044642.

42 Durando X, Farges MC, Buc E, Abrial C, Petorin-Lesens C, Gillet B, Vasson MP, Pezet D, Chollet P and Thivat E: Dietary methionine restriction with FOLFOX regimen as first line therapy of metastatic colorectal cancer: a feasibility study. Oncology 78(3-4): 205-209, 2010. PMID: 20424491. DOI: $10.1159 / 000313700$

43 Goseki N, Yamazaki S, Shimojyu K, Kando F, Maruyama M, Endo M, Koike $\mathrm{M}$ and Takahashi H: Synergistic effect of methionine-depleting total parenteral nutrition with 5fluorouracil on human gastric cancer: a randomized, prospective clinical trial. Jpn J Cancer Res 86(5): 484-489, 1995. PMID: 7790321. DOI: 10.1111/j.1349-7006.1995.tb03082.x

44 Kaiser P: Methionine dependence of cancer. Biomolecules 10(4), 2020. PMID: 32276408. DOI: 10.3390/biom10040568

Received November 13, 2021

Revised December 3, 2021

Accepted December 4, 2021 